\title{
Relationship Between Business Sustainability and Management Innovation
}

\author{
Sara Amin Tagelsir ABDELRAHMAN ${ }^{1^{*}}$, Md. Yusof ISMAIL ${ }^{1}$, Noor Azlinna AZIZAN², Abdul \\ Rahim ABU BAKAR ${ }^{2}$, Amjad M KHALILi ${ }^{3}$, Shahryar SOROOSHIAN ${ }^{4,5}$ \\ ${ }^{1}$ kulliyyah of Engineering, International Islamic University Malaysia, Malaysia, Email: tagelsirsara61@gmail.com \\ ${ }^{2}$ College of Business Administration, Prince Sultan University, Saudi Arabia \\ ${ }^{3}$ Palestine Technical University-Kadoorie (PTUK)Tulkarm, West Bank \\ ${ }^{4}$ Department of Business Administration, University of Gothenburg, Sweden \\ ${ }^{5}$ Saito University College, Malaysia \\ * Corresponding Author
}

Received: 29.07.2021

Accepted: 18.09.2021 Published: 07.11.2021

DOI: 10.47750/QAS/22.185.07

\begin{abstract}
Because of the large number of companies that enter the market on a daily basis and the new business trends, the business environment is always evolving. Companies must develop a flexible management system to respond to quick changes in order to maintain a competitive advantage in the market. To do so, businesses must constantly produce new ideas and suggest innovative ways to keep up with the market. Hence this work aimed to examined the link between management innovation and company sustainability. A case study was undertaken on a local manufacturing company that faces management innovation and business sustainability issues. The needed data was gathered through a questionnaire that was distributed to the company's employees. To extract the conclusions, the questionnaire results were analyzed using statistical techniques. The findings indicate that management innovation enhances organizational sustainable performance and drives sustainability. The finding is a usefull guide for entrepreneurs and company ploicy makers to necessitates continual management improvement.
\end{abstract}

Keywords: sustainability; business sustainability; sustainable performance; innovation; management innovation

\section{Introduction}

Because organizations must develop adaptable methods and tools to cope with the changing nature of the market, innovation is a critical tool for sustaining business in a competitive climate (Asim and Sorooshian, 2019). In business, innovation is vital not only in the product or service supplied by a company, but also in monitoring, controlling, and enhancing the performance of the many levels inside the company. The success of major organizations is linked to management innovations in the same way that it is credited to technology advances. Furthermore, management innovation entails changing the firm's organizational form and practices in a way that exploits the firm's technological expertise (Volberda et al., 2013). As a result, management innovation both supports and fosters technological innovation. Management innovation is defined as the development and execution of a new to the state of the art management practice, process, structure, or technology that is designed to achieve organizational goals (Birkinshaw et al., 2008). Despite the fact that management innovations are claimed to be important to business survival, research shows that efforts in studying and developing systematic outlines for management innovation are quite limited due to the difficulty in assessing the innovations effectiveness, as there is no direct discrete data that can be measured for evaluation. Furthermore, no concrete link has been established between the application of management innovation and the achievement of business sustainability.

The article aims to explain the concept of innovation in organisational management as a technique of lean management. Moreover, it shows the relationship between sustainability of the firm and management innovation. Besides, the study attempts to investigate the impact of management innovation on the sustainable performance of the organisation and the significance of this innovation for the business existence. Hence, in short, the research question for this study is: "Does there exist a relationship between management innovation and business sustainability?"

\section{Literature}

\section{Business Sustainability}

The term sustainability is defined as "a requirement of our generation to manage the resource base such that the average quality of life that we ensure ourselves can potentially be shared by all future generations"(Online Etymology Dictionary, 2020). When initially used, the concept was raising from an ethical perspective or the sense of responsibility towards forthcoming generations (WIERSUM, 1995). Therefore, sustainability denotes preserving resources to optimize their productivity. In other words, sustainability implies that the extraction levels of 
the recourse's benefits should be enough to meet the present needs without affecting the future natural balance of recourses. Sustainability consists of three pillars i.e., economy, environment and society (Keeble, 1987). Although concept of sustainability from the preceding discussion seems to be restricted to environmental matters, the concept is wide enough to involve all forms of resources because sustainability in fact is the continuation of state for a long time at a certain grade (Waseem \& Kota, 2017). Therefore, the concept is applied to business as well, since the continuation of evolvement is crucial for the business existence. Business sustainability is defined by as "the ability of firms to respond to their short-term financial needs without compromising their (or others') ability to meet their future needs" (Bansal \& DesJardine, 2014). In other words, business sustainability can be viewed as the achieving the balance in utilizing the different organization's resources

\section{Sustainable Performance}

Another term that is related to business sustainability is sustainable performance (Ayman Abu-Rumman, 2021). This term refers to the alignment or harmonization of the economic, environmental and social goals of the organization in the execution of core market operation with a vision of optimizing the value(Sustainable Business Partnership, 2020). The growing competitiveness in the marketplace has placed immense pressure on firms to constantly increase the quality of goods and services for consistent business expansion in order to promote the credibility of the firm. However, fulfilling these requirements calls for increased organisational efficiency by concentrating on quality and productivity enhancement, quality assurance and cost optimization(Randhawa \& Ahuja, 2017). Consequently, the sustainable performance will be achieved. Therefore, for organization to apply sustainable performance, it must count for the sustainability in three dimensions within and outside the organization scope, during the process of setting its vision, mission and strategies.

\section{Innovation}

Innovation has numerous definitions used in a sectors, such as academia, business, politics and community development (Taylor, 2017, Asim and Sorooshian, 2021). However, all the definitions agreed that the root of innovation concept is novelty of outcome, whether innovation is the outcome itself, or it is the process that generate this outcome. Innovation is linked to creativity, since creativity is defined as "a complex, cognitive process that involves finding and developing solutions to novel, ill-defined problems that will enhance the organization in the form of its products, services, processes, and procedures" (Waples \& Friedrich, 2006). Thus, creativity is the drive of innovation. In other words, innovation is the outcome of creativity. In organisational framework, innovation is not necessarily a new idea, it may be the implementation of an existing practice that is applied for the first time within the organization (De Vries et al., 2015). Further, the practice may not be novel to the organization but it has been improved in order to promote performance or create value, thus improve the competitive position (Asim et al., 2019).

\section{Relationship between Sustainability Performance and Innovation}

Some studies viewed innovation as a drive for sustainable performance (Adams et al., 2016), where the significance of implementing innovation in obtaining the sustainable performance is illustrated. Studies also showed that innovation has a positive impact on the organisation's performance, since it facilitates increasing the efficiency of materials and energy consumption, which satisfies the environmental and economic objectives of sustainability (Kuzma et al., 2020). Moreover, the concept of sustainability-oriented innovation "proposes to alleviate the tensions between the company's environmental, social, and financial objectives, which are often at odds with each other" (Michelino et al., 2019), this concept is introduced in business in order to increase the value for the society that greatly concerned with preserving recourses. That is because, if the innovation is threatening sustainability by any mean, it will face opposition from the public, since the sustainability awareness is dramatically increasing day by day. Thus, for an innovation to be accepted it should be contributing to sustainability outside the firm or at least should not cause damage. As a result, it will contribute to sustainability of the firm itself. Another illustration of innovation contribution in sustainability is that the willingness of a company to formulate creative solutions, whether these solutions rely on process, product or service innovations, these solutions can be seen as a substantial organizational asset. Utilizing this resource to come up with mechanisms to sustain creativity will result in performance improvement and achieving competitive advantage (Kuzma et al., 2020).

\section{Methodology \\ Research design}

The purpose of conducting the methodological study is to evaluate and achieve the objectives of the project which are; exploring the under-researched relationship between business sustainability and management innovation and study the impact of innovations on the performance that leads to sustainability. Unlike technological innovation, management innovation effectiveness cannot be assessed by conducting simple experimental tests to collect data and analyse them to validate the idea or concept and, approve the concept introduction to be executed, however, innovation needs to be introduced and implemented in real life situations to be validated. Therefore, the followed approach to examine the validation of the project assumptions is to study the impact of management innovation that is applied in an actual company's management systems.

The most suitable approach to conduct this research on innovation management is suggested to be a case study on particular company rather than surveying the implementation of innovation in several companies. That is due to the current situation of pandemic where no site visits or face to face interviews can be conducted because of the lockdown. Hence, selecting a single case to examine the assumptions is more convenient.

\section{Participants}

The criteria for selecting the company were; being world class manufacturing company, facing sustainability challenges in the three dimensions, increasing customer demand for the products, expanding business and distribution networks, accessible source of information, and possibility of gaining reliable response. The company that satisfied the case study company's characteristics is a medical gloves producer, which is known for being a manufacturer of some of the highest quality latex gloves available on the market today, the main products categories are surgical gloves, examination gloves, dental gloves, veterinary gloves and home care gloves. Due to the rapid growth of rubber gloves industry and increasing customers' demand, case company is facing continuous challenge of improving the products and maintaining successful business, which makes it a suitable choice for this case study. 


\section{Data collection tools}

Achieving business sustainability requires applying the sustainable performance in the three dimensions; environment, society and economy. However, to measure how sustainable the business is, the aspects of each dimension need to be evaluated. Business sustainability has a huge number of Key Performance Indicators (KPIs) (Hristov \& Chirico, 2019). However, in this research the KPIs are summarized and presented in Table 1.

\begin{tabular}{|l|l|}
\hline Dimension & Key Performance Indicators (KPIs) \\
\hline Environmental & $\begin{array}{l}\text { 1. Preservation of natural resources } \\
\text { 2. Waste management }\end{array}$ \\
\hline \multirow{3}{*}{ Social } & 1. Employees satisfaction \\
& 2. Employees retention \\
& 3. Employees motivation \\
\hline \multirow{5}{*}{ Economical } & 1. Cost management \\
& 2. Marketing effectiveness \\
& I.Product/service development \\
& I.Promotion and advertisement \\
& 3. Quality assurance \\
& 4. Return of investment \\
& 5. Cope with changes \\
\hline
\end{tabular}

Table 1: Sustainability Key Performance Indicators (KPIs)

Additionally, Measuring innovation is an exceptionally challenging process, since there is no single set of KPIs that fits all types of innovations. Consequently, innovations generally obtain their validations from the results of implementing them. Although there is no standard set of metrics to measure innovation, studies showed that the focus areas of management innovation are as shown below (Frey, 2008):

- Products: in determining product specifications and develop techniques to better study the market and understand customer requirements.

- Services: in increasing customers' satisfaction and increase the demand for what the company provides.

- Process: in improving the efficiency of providing services and producing products, and in increasing the productivity.

- Strategies, systems and structures: in setting reasonable gaols and putting plans to facilitate attaining these goals. Also, in organizing the company according to company's vision and mission.

- Value creating: in creating competitive advantage by efficient cost management and cost reduction techniques to attract consumers.

- Expansion: in speeding up the growth of the business and expand globally.

Hence, The study aims to achieve the targeted objectives by setting assumptions about the sustainable performance and management innovation and test the validity of these assumptions. The assumptions were made based on the literature review on business sustainability factors and sustainability metrics, also from the readings on management innovation in business improvement. These assumptions are: Innovation is vital for business sustainability.

Management innovation is as important as technological innovation for business sustainability. Management innovation is vital for environmental sustainability.

Management innovation is vital for social sustainability. Management innovation is vital for economical sustainability.

Although sustainable performance implies attaining sustainability within and outside the company, the study focuses on evaluating the impact of management innovation on sustainability dimensions inside the company only. To evaluate the validity of the proposed assumptions, the questionnaire was designed to approach the sustainable performance by testing management innovation significance for each of the sustainability dimensions. The dimensions are illustrated as business practices that represent these dimensions rather than being tested holistically. The questionnaire was distributed to employees and managers of different rankings and positions at the company. The first, section of the questionnaire aims to get details of the respondents and general structural information about the company of study. The second section aims to assess the assumptions by evaluating the importance of management innovation for sustainability performance by examining several business practices.

\section{Data Analysis}

The questionnaire used 5-points Likert items and Likert scale measurement to assess the responses. As shown earlier, innovation as a variable is difficult to be measured, especially management innovation which has not been studied profoundly and the findings from the conducted few studies are quite limited. Therefore, Likert scale measurement is the convenient approach whereas the results based on personal opinions. Analysing the data from responses is based on the assumptions made earlier. Some of the assumptions were tested using single questions while the others used multiple questions combined into single scales. The single questions measurement is known as Likert items and combined questions for single assumptions are called Likert scales (N. Boone Jr. \& A. Boone, 2012). The collected data have been analysed using Statistical Package for the Social Sciences (SPSS) and Microsoft Excel. The central tendency of Likert items was analysed using Mode, because the data measurement scale is ordinal, and the results are best displayed through bar charts. However, Likert scale data central tendency was measured using Mean since the data form intervals measurement scale. The Likert scale data can be displayed using histograms. The intervals of Likert scale data are shown in Table 2 below (Pimentel, 2010): 


\section{GENERAL MANAGEMENT}

\begin{tabular}{|l|l|l|}
\hline Likert-Scale Description & Likert-Scale & Likert Scale interval \\
\hline Strongly Disagree & 1 & $1.00-1.80$ \\
Disagree & 2 & $1.81-2.60$ \\
Neutral & 3 & $2.61-3.40$ \\
Agree & 4 & $3.41-4.20$ \\
Strongly Agree & 5 & $4.21-5.00$ \\
\hline
\end{tabular}

Table 2: Likert Scale Measurements

\section{Result}

The questionnaire was completed by 37 respondents occupying managerial positions at the case company. The questionnaire consists of 16 questions divided into three groups. Each group evaluates some of the assumptions of this study.

The first question Likert item in the questionnaire aims to know the respondents opinions about the impact of innovation on business in general to assess the first assumption, which claims that innovation is vital for business sustainability. The responses are presented in the bar chart in Fig. 1 below. From the bar chart it can be seen that the mode value is 5 , with frequency of 15 , which means around $40.5 \%$ of the respondents strongly support the statement. Furthermore, 13 of the responses were 4 , making it the second highest frequency, which comprises around $35 \%$ of the responses. Therefore, around $75 \%$ of the responses were agreements with the assumption, while only $5.4 \%$ (2 responses) disagreed.

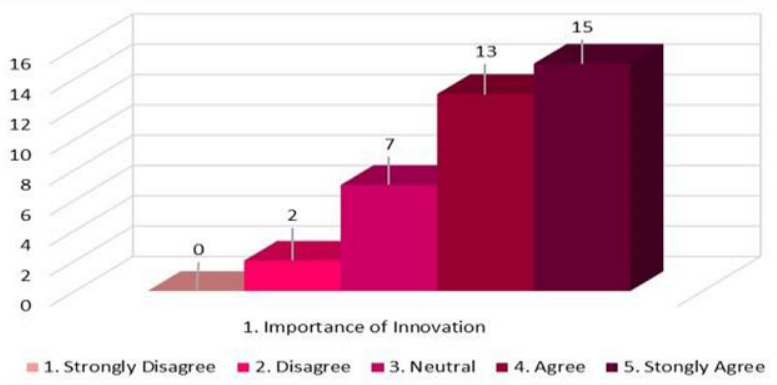

Fig. 1: Importance of Innovation

The second part of the questionnaire consist of three Likert items. This part assesses the second assumption which states that management innovation is as important as technological innovation for business sustainability. To compare technological and management innovations, the importance of each was assessed first in separate questions. The results of these two questions are presented in Fig. 2. Technological innovation has two modes which are 4 and 5 with a frequency of 14 each. However, management innovation has one mode which is 5 with a frequency of 17 , followed by a frequency of 11 for 4 . Although the frequency of 5 (Strongly Agree) is higher in management innovation, the total count of agreements is the same in both technological innovation and management innovation (28 of the responses), which implies that equal number of respondents (around 75\%) agree to each of the questions statements. On the other hand, the total counts of disagreements from the two questions equate ( 1 respondent each), however, the 1 response in technological innovation disagrees, while the one from management innovation strongly disagrees. The percentage of disagreements from each of the questions is around $2.7 \%$.

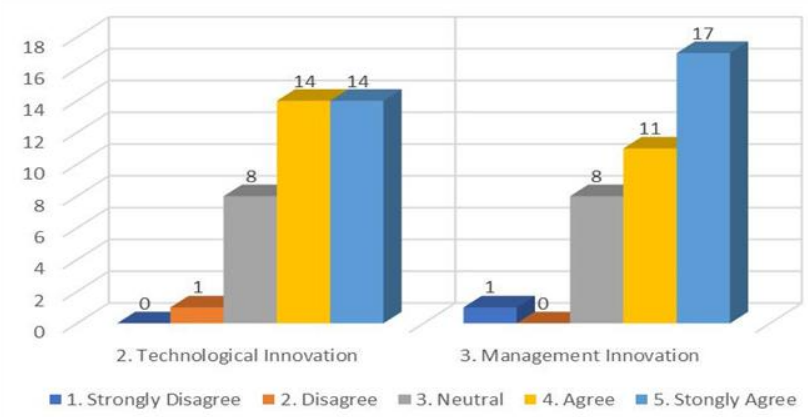

Fig.2: Importance of Technological Innovation \& Management Innovation

In order to assure the accuracy of the results of the previous comparison, respondents were asked directly in the following question to assess the statement "Management innovation is equally important to technological innovation for company's survival". The responses to the statement are illustrated by the pie chart in Fig. 3 below. The mode value is 5 (17 of the responses), and the second highest frequency is for 4 (13 of the responses). Therefore, over $80 \%$ of the responses were agreements with the statement. 


\section{GENERAL MANAGEMENT}

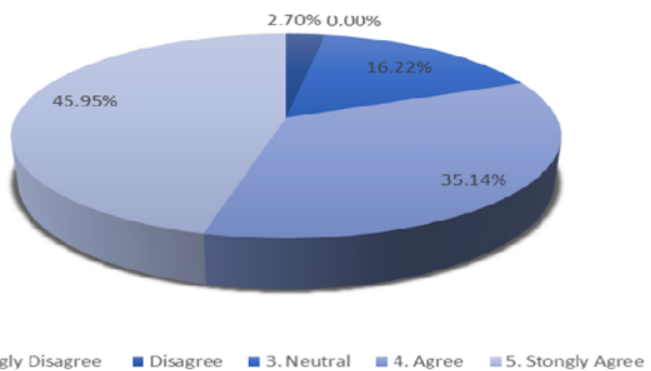

Fig.3: Equality of Technological Innovation \& Management Innovation Importance

The agreement percentages from both of the individual assessments comparison and the single question comparison are above $75 \%$.

The last part of the questionnaire assesses the importance of the management innovation for business sustainability in its three pillars. The evaluation of management innovation was based on the KPIs of sustainability. Although the three pillars are included, targeted variable of the assessment is business sustainability as a whole rather than its components.

Since multiple Likert items are combined to extract conclusion about a single variable (business sustainability), the measurements of Likert scale were used. The mean of each respondent answers was calculated and the results are shown in the histogram in Fig 4.

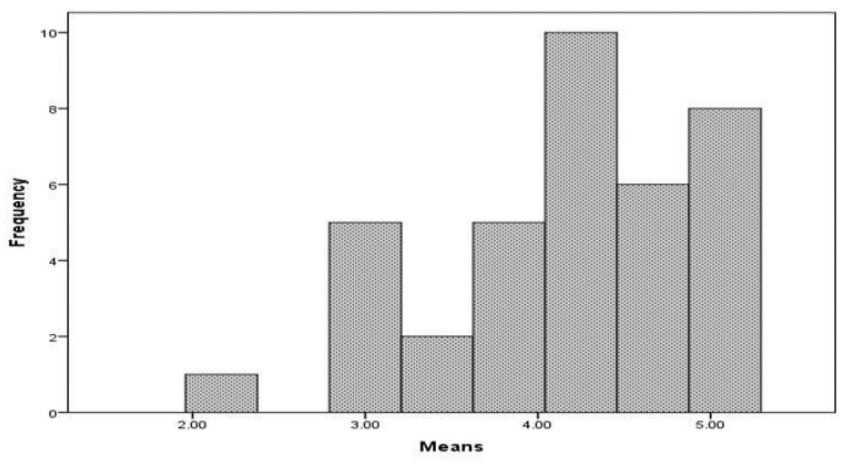

Fig.4: Histogram of Means' Frequencies

From the histogram, it can be seen that most of the responses are in the between 4 and 5 , which are the ranges of agreement. The mean score of the responses is 4.18 , referring to Table 2 this mean falls in the interval of Agree (3.41 - 4). The 25th percentile is 3.83 is also within the 4 th (Agree) interval. This indicates that over $75 \%$ of the responses were agreements. To give a better picture of the responses, a pie chart of responses percentages is illustrated in Fig. 5. Fig. 5 shows that around $77 \%$ of the responses agreed that management innovation positively impact the business sustainability.

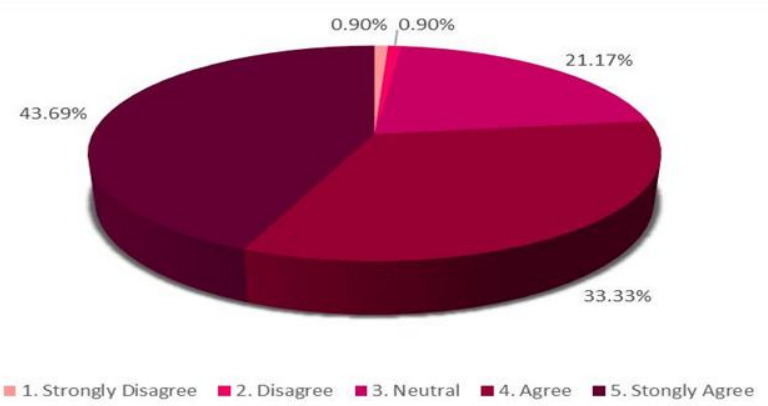

Fig.5: Total responses on The Impact of Management Innovation on Sustainability

\section{Discussion and Conclusion}

The purpose of this study was to look into the relationship between management innovation and company sustainability, as well as the impact of management innovation on a firm's long-term success. The case study findings confirmed the existence of a beneficial association between management innovation and business sustainability. Furthermore, the findings underlined the need of management innovation in ensuring business sustainability.

Some other studies are supporting the finding of this study, such as "Sustainability-oriented Innovation" that sees innovation as a driving force for long-term success (Adams et al., 2016), Kuzma et al. (2020), which demonstrated that innovation has a considerable and beneficial impact on overall organizational 
sustainability and on long-term performance in each of the elements of sustainable development. Furthermore, the concept of sustainability-oriented innovation by Michelino et al. (2019), Lüdeke-Freund, F. (2020) when explained business models for sustainability innovation ; and the discussion on Social innovation and social entrepreneurship (Farinha et al.,2020) are in line with the finding of this study.

The responses from the first part of the questionnaire of this study verified that innovation is vital for business sustainability. From the results in Fig. 2, most of the respondents (75\%) consent that the two types of innovations are equally significant. Also Fig. 3 showed that around $80 \%$ of the respondents think that management innovation is equally important to technological innovation. Therefore, the second assumption was validated. Furthermore, according to the responses of the last part of the questionnaire the mean of respondents' score is within the agreement interval. Thus, most of the respondents agree that management innovation promotes the business sustainability, which proves the last three assumptions.

Our research reslts have implications for both practitioners and policy-makers. From the previous discussion, it can be concluded that there is a positive relationship between management innovation and business sustainability. Furthermore, it can be deduced that innovating new techniques of administrating the company has an equal impact on business success as improving the technological sector. Finally, the results demonstrate that in order to preserve the business constancy, administrators should invest in promoting innovation in the management practises and strategies in running the company in general, and in each of the company's department and subdivisions.

Finally, the findings revealed that management innovation is equally important to firm survival as technological innovation. Nonetheless, the fundamental flaw of this study, which should be considered for future research, is that it evaluated the relevance of management innovation as a whole rather than breaking it down into its components. Another limitation of the study was that it treated corporate sustainability as a single variable. As a result, the influence of management innovation on each of the three pillars of sustainability has yet to be demonstrated.

\section{Acknowledgment}

The authors thank Prince Sultan University for covering the publication fees.

\section{References}

[1] Adams, R., Jeanrenaud, S., Bessant, J., Denyer, D., \& Overy, P. (2015). Sustainability-oriented Innovation: A Systematic Review. International Journal of Management Reviews, 18(2), 180-205. doi:10.1111/ijmr.12068

[2] Asim, Z., \& Sorooshian, S. (2019). Exploring the Role of Knowledge, Innovation and Technology Management (KNIT) Capabilities that Influence Research and Development. Journal of Open Innovation: Technology, Market, and Complexity, 5(2), 21. doi:10.3390/joitmc5020021

[3] Asim, Z., \& Sorooshian, S. (2021). Innovation Management Capabilities for R\&D in Pakistan. Advances in Logistics,

Operations, and Management Science, 2724-2734. doi:10.4018/978-1-7998-3473-1.ch188

[4] Asim Z, Sorooshian.S, Shahid Ahmad M, (2019). Publication Trends on Overlapping Boundaries among Capabilities related to Knowledge, Innovation and Technology Management in R\&D Context, International Journal of Recent Technology and Engineering, 7(6): 352-363.
[6] Abu-Rumman, A., Al Shraah, A., Al-Madi, F., \& Alfalah, T. (2021). Entrepreneurial networks, entrepreneurial orientation, and performance of small and medium enterprises: are dynamic capabilities the missing link? Journal of Innovation and Entrepreneurship, 10(1). doi:10.1186/s13731-021-00170-8

[7] Bansal, P., \& DesJardine, M. R. (2014). Business sustainability: It is about time. Strategic Organization, 12(1), 70-78. doi:10.1177/1476127013520265

[8] Birkinshaw, J., Hamel, G., \& Mol, M. J. (2008). Management Innovation. Academy of Management Review, 33(4), 825-845. doi:10.5465/amr.2008.34421969

[9] DE VRIES, H., BEKKERS, V., \& TUMMERS, L. (2015). INNOVATION IN THE PUBLIC SECTOR: A SYSTEMATIC REVIEW AND FUTURE RESEARCH AGENDA. Public Administration, 94(1), 146-166. doi:10.1111/padm.12209

[10] Farinha, L., Sebastião, J. R., Sampaio, C., \& Lopes, J. (2020). Social innovation and social entrepreneurship: discovering origins, exploring current and future trends. International Review on Public and Nonprofit Marketing, 17(1), 77-96. doi:10.1007/s12208-020-00243-6

[11] Frey, C. (2008). How do you Measure Innovation Results and Outcomes? In InnovationManagement.

[12] Hristov, I., \& Chirico, A. (2019). The Role of Sustainability Key Performance Indicators (KPIs) in Implementing Sustainable Strategies. Sustainability, 11(20), 5742. doi:10.3390/su11205742

[13] Keeble, B. R. (1988). The Brundtland report: "Our common future." Medicine and War, 4(1), 17-25

[14] Kuzma, E., Padilha, L. S., Sehnem, S., Julkovski, D. J., \& Roman, D. J. (2020). The relationship between innovation and sustainability: A meta-analytic study. Journal of Cleaner Production, 259, 120745. doi:10.1016/j.jclepro.2020.120745

[15] Lüdeke-Freund, F. (2019). Sustainable entrepreneurship, innovation, and business models: Integrative framework and propositions for future research. Business Strategy and the Environment, 29(2), 665-681. doi:10.1002/bse.2396

[16] Michelino, F., Cammarano, A., Celone, A., \& Caputo, M. (2019). The Linkage between Sustainability and Innovation Performance in IT Hardware Sector. Sustainability, 11(16), 4275. doi:10.3390/su11164275

[17] N. Boone Jr., H., \& A. Boone, D. (2012). Analyzing Likert Data. Journal of Extension, 50(2), 1456-1466. https://doi.org/10.1007/s11172-017-1908-3

[18] Online etymology dictionary. (2003). Choice Reviews Online, 41(02), 41-0659-41-0659. doi:10.5860/choice.41-0659

[19] Pimentel, J. (2010). A note on the usage of Likert Scaling for research data analysis. Usm R \& D, 18(2), 109-112. www.raschanalysis.com/rasch-model-specification.htm

[20] Randhawa, J. S., \& Ahuja, I. S. (2017). 5S - a quality improvement tool for sustainable performance: literature review and directions. International Journal of Quality \& Reliability Management, 34(3), 334-361. doi:10.1108/ijgrm-03-2015-0045

[21] Sustainable Business Partnership. (2020). Sustainable Performance. http://sbpltd.uk.com/services-page/sustainableperformance/

[22] Taylor, S. P. (2017). What Is Innovation? A Study of the Definitions, Academic Models and Applicability of Innovation to an Example of Social Housing in England. Open Journal of Social Sciences, 05(11), 128-146. doi:10.4236/jss.2017.511010

[23] Volberda, H. W., Van Den Bosch, F. A. J., \& Heij, C. V. (2013). Management Innovation: Management as Fertile Ground for Innovation. European Management Review, 10(1), 1-15.

[24] Waples, E. P., \& Friedrich, T. L. (2011). Managing Creative Performance. Advances in Developing Human Resources, 13(3), 366-385. doi:10.1177/1523422311424713

[25] Waseem, N., \& Kota, S. (2017). Sustainability De fi nitions - An Analysis Á De fi nitions Á Spatial Á Temporal Á Global Á Local Á. 2. https://doi.org/10.1007/978-981-10-3521-0

[26] Wiersum, K. F. (1995). 200 years of sustainability in forestry: Lessons from history. Environmental Management, 19(3), 321. 